\title{
CARNAVAL ANDINO EN LA CIUDAD DE ARICA: PERFORMANCE EN LA FRONTERA NORTE CHILENA
}

\author{
Andrea Chamorro
}

\section{* Introducción}

Resumen

Las investigaciones realizadas en el Norte Grande de Chile han relevado la capacidad de adaptación y reconstrucción de los entramados sociales y culturales andinos en contextos de complejidad urbana. En este escenario, a partir de una etnografía de las performances del Carnaval Andino "Inti Ch'amampi, Con la Fuerza del Sol" realizado en Arica, observamos que estas prácticas expresivas reelaboran los sentidos étnicos asociados a la fiesta, constituyendo estrategias de comunicación o autorrepresentación que sitúan la diferencia étnica respecto a interlocutores nacionales en un espacio social y simbólico transfronterizo.

Palabras claves: carnaval - performance - aymara - Arica Andes Centro-Sur.

Abstract

Research in north Chile has revealed the capacity of Andean social networks for adaptation and reconstruction in contexts of urban complexity. In this context, based on an ethnography of Andean Carnival performances of the "Inti Ch'amampi, Con la Fuerza del Sol" in Arica, we saw how these expressive practices re-elaborated ethnic sensibility related to the event, constituting a novel strategy for communication or self-representation that situated the different ethnic groups with respect to national speakers in a given social space and symbolic border crossing.

Key words: carnival - performance - Aymara - Arica - South Central Andes. Recibido: octubre 2012. Aceptado: marzo 2013.

\footnotetext{
1 Programa Doctorado en Antropología, Universidad Católica del Norte. Gustavo Le Paige 380, San Pedro de Atacama, CP 141000o, CHILE. Email: andrea_achp@yahoo.com

2 La región de Arica y Parinacota fue segregada de la región de Tarapacá, siendo promulgada como tal por la ex Presidenta de la República de Chile, Michelle Bachelet, el 23 de marzo de 2007, mediante la Ley 20.175.
} la región de Arica y Parinacota, y el límite norte de Chile respecto a la frontera que mantiene con Perú y Bolivia (Figura 1) ${ }^{2}$. Este espacio geopolítico se constituye a partir de la ocupación militar chilena del territorio sur peruano durante la Guerra del Pacífico (1879-1883); pero allí se constata que la presencia de empresarios chilenos (p.e., Edwards, Ossa, Urmeneta, Causiño, Puelma) con anterioridad a 1879 , era superior a la de compañías inglesas, francesas y alemanas (Podestá 2004). Con ello, el potencial bélico permitió asegurar la propiedad de los recursos salitreros correspondientes a lo que fuera el departamento de Tarapacá.

Consecuentemente, la dimensión estratégica para asegurar la propiedad territorial y ejercer soberanía combinó factores militares, políticos, sociales y simbólicos de incorporación de las poblaciones sometidas (indígenas, afro-descendientes, mestizos y criollos peruanos) al ideario de la nación chilena. La instauración del servicio militar obligatorio y la intensiva fundación de escuelas públicas constituyeron dispositivos de asimilación que establecieron los signos y calendarios patrios como hitos simbólicos de la sociabilidad e identidad, transformando irremisiblemente los modelos de organización y autoridad tradicional de las comunidades (Tudela 1990; Van Kessel 2003). De este modo, "los colores de la bandera chilena (blanco, azul y rojo) reemplazan el blanco y rojo 


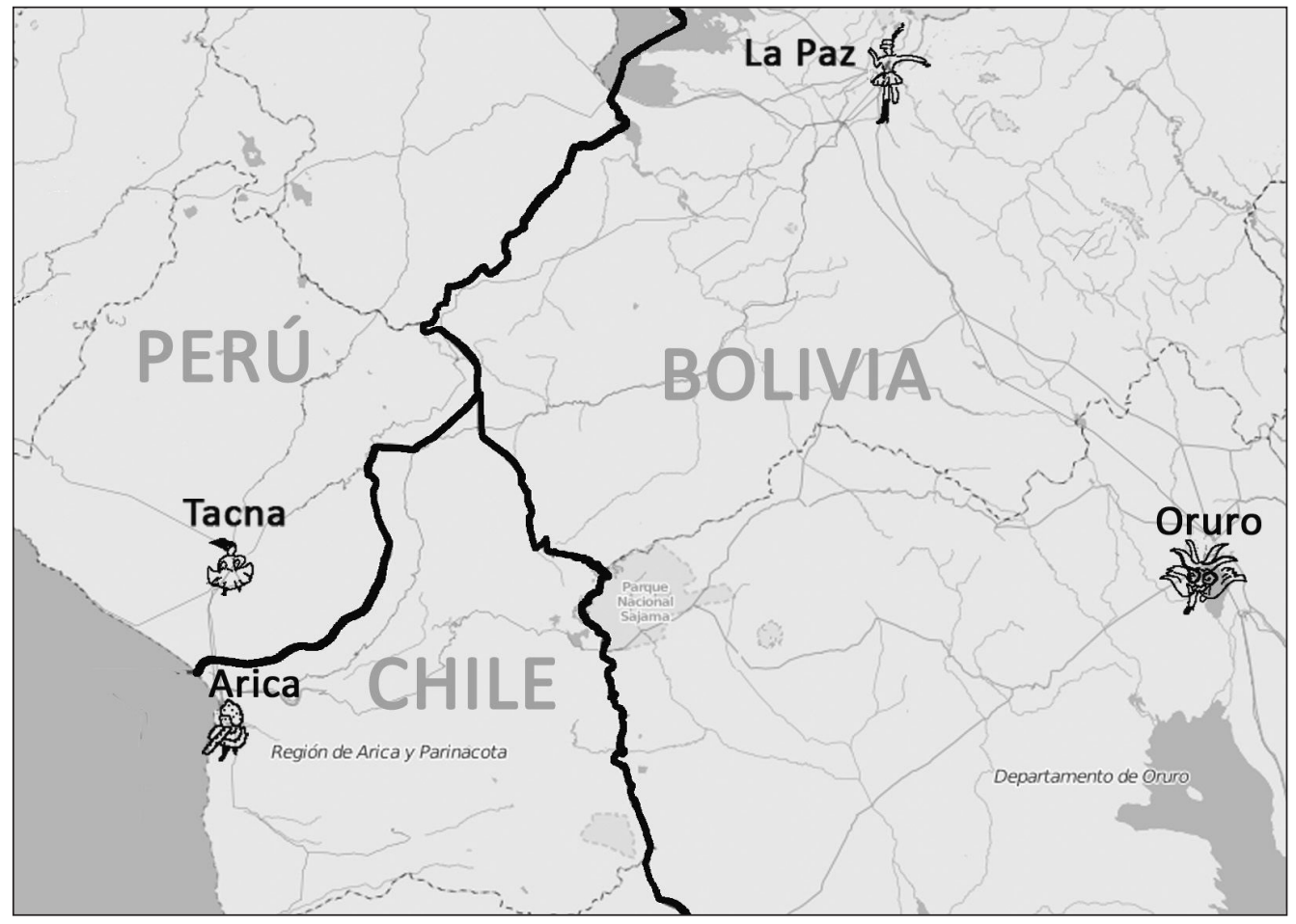

Figura 1. Mapa de ubicación de la ciudad de Arica, en el que se indican algunas de las ciudades con las que actualmente mantiene intercambio ritual y festivo transfronterizo.

del estandarte peruano; los altares de las capillas son retocados y adornados con banderas chilenas" (Tudela 1990: 11).

Sin embargo, ha sido posible observar que la población indígena construyó sus propias estrategias de integración, comenzando a demandar instrucción escolar y militar como vías que garantizaran sus competencias como ciudadanos legítimos (Gundermann 1997). En un mismo sentido, conciliaron el desarrollo de sus prácticas expresivas tradicionales - como la realización pública de fiestas a santos patronos y carnavales- respecto de las medidas de control de las autoridades chilenas (Díaz et al. 2004). En este sentido, con la incorporación al servicio militar, no solo aprenden a "leer, escribir y querer Chile" (Tudela 1990), sino que también acceden a la formación como músicos en las "bandas de guerra", introduciendo:

"[...] a sus prácticas culturales comunitarias nuevas expresiones musicales, como marchas o pasacalles, para acompañar procesiones, himnos marciales y religiosos en honor a los santos patronos, fanfarrias (dianas en la versión local), para destacar ciertos momentos rituales ofestivos, y adaptación de melodías y ritmos tradicionales (como huaynos) a la interpretación con instrumentos de bronce, para amenizar las celebraciones en la casa del alférez o en el parabién (local)" (Díaz 2009: 384).

Estos procesos nos permiten entrever las complejas relaciones sociales, culturales y afectivas que las poblaciones sometidas comienzan a desarrollar respecto a las instituciones, prácticas y discursos de poder chilenos.

No obstante, con posterioridad a las políticas de anexión del territorio tarapaqueño y tras la firma del Tratado de Lima (1929), que establece la soberanía sobre Arica:

"[...] las poblaciones indígenas se hacen demográficamente minoritarias en favor de un creciente proletariado, capas mediasy propietarios con extracción étnica y nacional distinta que establecen fronteras étnicas ("indio"y "blanco"o "chileno") diferentes a las que se habian venido desarrollando" (Gundermann 1997: 21). 
De este modo, una población socialmente heterogénea ubicada en la costa estigmatizará a todos los poblados agrícolas del interior (valles, precordillera y cordillera) como "indios", aunque sus habitantes no se consideren como tales (González y Gundermann 1996; Gundermann 1997). De esta manera, se recomponen identidades étnicas cuya ambigüedad se articula en torno a la definición exógena de su particularidad como extranjera, lo cual deriva en un estereotipo de sus características étnicas que serán experimentadas como estigma (González y Gavilán 1990; González y Gundermann 1996; González 1997; Gundermann 1998).

Al respecto, debemos considerar que "entre los años 1930 y 1950 , el Estado tuvo poco interés por desarrollar la zona, vale decir, no se esforzó por invertir, fortalecer la infraestructura y dinamizar su economía" (Podestá 2004: 130). Entonces, la propiedad territorial todavía estaba en cuestión ${ }^{3}$. Con la crisis del salitre las inversiones se concentraron en la zona central del país, si bien se privilegió en términos económicos la región de Antofagasta, donde se encontraba el mineral de Chuquicamata. No obstante, a partir de los años 50 se perfila un nuevo interés geopolítico. El presidente Carlos Ibáñez del Campo otorga al puerto de Arica -creado en 1945- la condición de Puerto Libre, lo que permite importar todo tipo de productos sin gravamen. En 1958, durante la administración de Jorge Alessandri se instituye la Junta de Adelanto de Arica, con lo cual se fomenta el desarrollo regional. Estrategias económicas y de industrialización -automotriz, conservera y de productos del mar, principalmente-, transforman a la ciudad en un polo de migración para la población del interior, lo que se mantiene hasta 1973.

En este contexto, la población indígena -fundamentalmente de origen aymara- de precordillera y altiplano participará tangencialmente de los procesos de industrialización articulando economías familiares de pequeña escala (por cuenta propia y economía informal): comercio agropecuario y de abastos, comercio ambulante y trans-

3 La inestabilidad política de Perú durante los años 30 dificultó la implementación del Tratado de Lima, y entre los años 1920 y 1940 Bolivia reivindicó los recursos hídricos de la región. "Hechos que fundamentaron la imagen de una zona con inestabilidad política, militar y económica" (Podestá 2004: 130). porte campo-ciudad (González 1995). Hacia fines de la década de 1960, migrantes provenientes del altiplano chileno y boliviano se han instalado no solo en la ciudad de Arica, sino que también como agricultores en los valles de Azapa y de Lluta ${ }^{4}$. De esta manera:

"[...] el trabajo no sujeto a horarios ni requerimientos tan estrictos, característico de las actividades por cuenta propia de tipo familiar, les permite a muchos seguir unidos a sus lugares de origen y su cultura rural de proveniencia: sea económicamente (directamente a través de la producción agropecuaria o indirectamente por medio de la mantención de bienes y derechos) o culturalmente (mediante la participación socio-organizativa y festivo-religiosas)" (González 1995: 316).

Progresivamente, los propios indígenas entroncarán la construcción de diferencias étnicas con la apelación a diversos recursos culturales (parentesco, lenguaje, religión, modo de vida) que revalorizan y actualizan en la ciudad. Como parte de este proceso resultará especialmente profusa y generalizada la recreación de prácticas expresivas -fundamentalmente danzas y música- en función de la reproducción y manifestación social de pertenencias identitarias (Chipana 1986; Grebe 1986; González y Gavilán 1990; Tabilo et al. 1995; González 2003).

Hacia la década de 1980, la dictadura militar (19731990) impone una nueva política de resguardo de fronteras y una idea de integración nacional, por lo que las políticas de asimilación cultural se intensifican (Zapata 2001). Asimismo, surgen las primeras organizaciones culturales aymara de carácter étnico-reivindicativo que junto con denunciar la discriminación y demandar reconocimiento en torno a la creación de políticas públicas específicas (educación, salud, derechos de agua, entre otros), impulsan trabajos de revalorización de sus prácticas y costumbres en espacios urbanos (reinterpretación de los bailes, los rituales, la lectura de la hoja de

4 Como parte de las obras de la Junta de Adelanto, "se mejora y amplía infraestructura de riego y se agranda la frontera agrícola a través de obras de drenaje y conducción de agua con el valle de Lluta y de canalización de aguas en los de Azapa y Camarones" (Zapata 2001: 93). Esto es aprovechado por migrantes aymara provenientes de la precordillera y cordillera (Platt 1975; Informe de la Comisión de Verdad Histórica y Nuevo Trato con los Pueblos Indígenas 2008). 
coca, entre otros). Con ello, apelan a la construcción de narrativas históricas que permitan unificar a los pueblos aymara, siendo especialmente significativa la integración ideológica indianista que se produce con dirigentes e intelectuales indígenas bolivianos durante este proceso (González y Gundermann 1996).

Con el retorno a la democracia en 1990, primero la Comisión Especial de Pueblos Indígenas (CEPI) y luego la formulación de la Ley Indígena 19.253 en el año 1993 , permiten asentar públicamente una conciencia étnica amplificada (Gundermann et al. 2005) a la vez que, significativamente, la acción estatal se etnifica (Gundermann 2003). Por lo que:

"[...] quienes hoy se reconocen como aymaras y atacameños reclaman el derecho a sostener públicamente una pertenencia étnica, así como a mantener y desarrollar aquellas prácticas sociales y culturales que los distinguen de la cultura nacionaly la sociedad chilena en general, a la cual buscan integrarse desde esta diferencia" (Zapata 2004: 173).

En síntesis, tras la Guerra del Pacífico los procesos de construcción de soberanía en Tarapacá posibilitan que población aymara migrante se asiente preferentemente en los valles y ciudades costeras del Norte Grande, como Arica e Iquique 5 . Desde allí, afianzan relaciones económicas, parentales y sociales como vehículo de sobrevivencia material, simbólica y afectiva frente a la visión descalificadora y prejuiciada de la sociedad criolla y/o mestiza chilena. Pese a ello, en algunos casos:

"[...] el contacto con la pobreza y la marginalidad urbana, junto a la discriminación y el estigma, han determinado que algunos aymara hayan preferido 'blanquearse' para acercarse a lo chileno, renegando de su condición indígena" (González y Gavilán s/f: 3).

Lo anterior alude no solo a una transformación de las señas corporales de etnicidad (cambios en peinados y color de cabello, maquillaje, vestimentas, actitudes, entre otros), sino que también a la activa participación en los procesos de modernización y asimilación, donde:

\footnotetext{
5 Según el Censo 2002, la población aymara representa un 7\% de la población indígena de Chile, correspondiendo a un total de 48.501 personas. De éstas, 38.072 residen en las ciudades de manera permanente (INE 2003).
}

"[...] el ascenso económico y social que supone la posibilidad de insertarse mejor en valles y ciudades, tener residencia urbana, educar mejor a los hijos o traer luz eléctrica, agua potable o plazas a los pueblos, etc..., pueden operar para alounos como mecanismo de superación de las condiciones de 'atraso', acercándose con esa postura 'modernizante' a la sociedad regional" (González y Gavilán 1990: 155).

Por otra parte, los aymara también crearon organizaciones económicas, locales y culturales con las cuales no solo mejoraron social, económica y afectivamente las condiciones de inserción en la ciudad, sino que también procuraron su continuidad y reproducción socio-simbólica en espacios urbanos (González y Gavilán s/f; Tabilo et al. 1995; González y Gundermann 1996), a la vez que garantizaron su representación y legitimidad ante el Estado (Gundermann y Vergara 2009). Es más:

"[...] los aymara del norte de Chile tienen un territorio simbólico construido en las ciudades a través de organizaciones que representan sus localidades y regiones y esto hace que se denote una organización social específica. Se realizan fiestas barriales, se conquista el espacio urbano a través de fiestas familiares y comunales realizando los matrimonios y ritos, en general, como formas de reconstrucción y reproducción de la etnia" (Zapata 2001: 62).

En lo que respecta a las organizaciones culturales, se crean centros de "hijos de pueblo", cofradías religiosas, asociaciones culturales y deportivas, organizaciones étnico-reinvindicativas, entre otras. Sus objetivos principales fueron:

"[...] la revaloración cultural (fiestas, tradiciones, costumbres) y la formulación de un proyecto histórico de constitución como pueblo. En este último caso, las demandas que tienen, además de las propiamente culturales, son étnico-reivindicativas. Apuntan a la recuperación y promoción de la etnicidad como alteridad legitima" (Zapata 2001: 103).

Con ello, no solo expresa la identificación con los lugares de origen, sino que, fundamentalmente, la formulación de demandas en los términos de una ciudadanía diferenciada (Gundermann 1997, 2003; Gundermann y Vergara 2009).

Respecto del escenario de frontera descrito, exploramos el Carnaval Andino "Inti Ch'amampi, Con la Fuer- 
za del Sol", desarrollado en la ciudad de Arica, como una festividad urbana que es fruto de la capacidad de gestión, organización y coordinación de las más de 40 agrupaciones aymara de bailes folclóricos andinos pertenecientes a la comuna de Arica ${ }^{6}$. Desde el año 2002, éstas preparan de manera autónoma los bailes y "entrada del carnaval", negociando con el gobierno local tanto las condiciones de producción del espectáculo como los sentidos del mismo.

\section{* Performance e investigación etnográfica}

El término general de performance deviene en un campo teóricamente inclusivo y culturalmente revelador que comienza a ser usado más ampliamente para hablar de dramas sociales y prácticas incorporadas, las cuales encontrarían definiciones específicas en correspondencia con las diversas tradiciones culturales.

"[Su] base teórica subyacente es suficientemente clara: actividades humanas - sucesos, conductas- que tienen la cualidad de lo que llamo 'conducta restaurada', o 'conducta practicada dos veces; actividades que no se realizan por primera vez sino por segunda vezy ad infinitum" (Schechner 2000: 13).

Sin embargo, y es su paradoja fundamental, ninguna repetición es exactamente lo que copia; pues los sistemas están en flujo constante. Se trata, por lo tanto, de "cintas de conductas" (Schechner 2000: 13) que existen aparte de los actores que las realizan; por ello se pueden guardar, transmitir, manipular y transformar.

De este modo, las performances -en palabras de Citro (2009)- aluden a "repertorios de memorias corporizadas" donde las manifestaciones expresivas (gestos, palabras, movimientos, danzas, cantos, ritos u otros) son medios vitales de acumular y transmitir saber social y sentidos de identidad; con ello "reproducen y transforman los códigos heredados, extrayendo o transformando imágenes culturales comunes de un 'archivo'

6 Entre las asociaciones de baile se cuenta con la participación de organizaciones y comparsas afro-ariqueñas, las que se han ido posicionando notoriamente en este espacio festivo. Sin embargo, referencias a su emergencia y proyecciones escapan de los marcos de este trabajo (ver p.e., León 2012; Báez 2010). colectivo" (Taylor 2001, cit. en Citro 2009: 35). En estos casos, las performances son acontecimientos sociales nunca separados de la actividad comunitaria, por lo que representan la identidad de un grupo a la vez que la construyen.

En un mismo sentido, para Cánepa (2001) las dimensiones simbólicas, sensoriales y emotivas de la performance le otorgan al actuante la posibilidad de ponerse al margen de los esquemas de su vida reglamentaria; posición liminal que le permite reflexionar sobre roles y estatus de la vida cotidiana revelando con ello sus propias estrategias de comunicación. Como cuerpos puestos en acción, afirma que:

"[...] a diferencia de lo que está permitido en el lenguaje, cuando el cuerpo es utilizado como medio para representar a 'otro' o a un hecho pasado, es imposible mantener la distinción entre el medio y el mensaje; es decir, entre el cuerpo como medio de la representación y el cuerpo objeto de la representación. Es justamente esta cualidad corporal la que otorga eficacia a las formas de representación performadas como espacios para la constitución de identidady memoria" (Cánepa 2001: 18).

Ahora bien, una etnografía de las performances del Carnaval Andino supone aproximarse a la perspectiva de los actores desde el campo de sus prácticas significativas; en este caso, memorias que se expresan a través de los cuerpos. De este modo, apelamos a una construcción dialógica y reflexiva de conocimiento, donde:

“[...] la participación es, pues, no solo una herramienta de obtención de información, sino el proceso mismo de conocimiento de la perspectiva del actor, pues éste es el que abre las puertas y ofrece las coyunturas culturalmente válidas para los niveles de inserción y aprendizaje del investigador" (Guber 2005: 188).

Dentro de este esquema reconocimos en la entrevista antropológica la principal herramienta de construcción de datos y aproximación etnográfica a las preguntas de investigación. La observación etnográfica y la participación u observación participante desde el rol de "antropólogabailarina", son, por su parte, las principales técnicas de investigación empleadas. 


\section{* El Carnaval Andino y la expresión de DIFERENCIA}

Los antecedentes del Carnaval Andino "Inti Ch'amampi, Con la Fuerza del Sol" se hallan en la trayectoria de instalación de migrantes aymara tanto en el valle de Azapa como en la ciudad de Arica (Figura 2). En este marco, se observa que al tiempo que los aymara de origen boliviano mantuvieron los lazos afectivos y socio-simbólicos con sus pueblos y nación de origen a través de la actualización de sus memorias expresivas en espacio chileno, los aymara chilenos se vincularon periódicamente con sus pueblos a través de organizaciones culturales y religiosas, siendo especialmente relevantes los calendarios litúrgicos cristianos.

En el valle de Azapa, los aymara bolivianos crearon grupos de música y danza de tarkeadas ${ }^{7}$ y junto a familias afro-descendientes organizaron el primer carnaval, representando la figura del No Carnavalón o "espíritu de los cultivos" a través de un muñeco de paja, cuyo símil sería la figura de un jornalero o campesino (Grebe 1986) ${ }^{8}$. Resulta ejemplar que estas primeras agrupaciones refieran sus nombres a los pueblos de origen en Bolivia, como es el caso de la agrupación Andino Sajama que alude a la provincia de Sajama, departamento de Oruro.

"[...] en el año 1970 ya habian tres agrupaciones, también salió San Pedro de Totora porque se juntaron de a... grupo, por ejemplo yo soy de San Pedro de Totora entonces esta gente... ya juntémonos somos de esta agrupación, los que somos del pueblo de Sajama hagamos esta agrupación y así, a pesar de que esos pueblos estaban en Bolivia, se identificaban acá y mostraron sus tradiciones, sus costumbres" (Bailarín de Hijos de Saxamar y Morenada San Pedro de Totora, vicepresidente de la Confraternidad).

En tanto, los aymara que se instalan en la ciudad de Arica se ubican en sectores periféricos: las poblaciones San José, Chile y Cabo Aroca. Sin embargo, a la vez que barrios y escuelas se transforman en lugares de acogida, también se constituyen en lugares de discriminación étnica. Frente a esta situación, los migrantes responden

7 La tarkeada es una danza autóctona tocada y bailada en Bolivia, Perú y Chile.

8 Se estima que el primer muñeco fue confeccionado en 1966 y que desde esa fecha se celebra año a año su desentierro y entierro en el pueblo San Miguel de Azapa (Recabarren y Valera 2006).

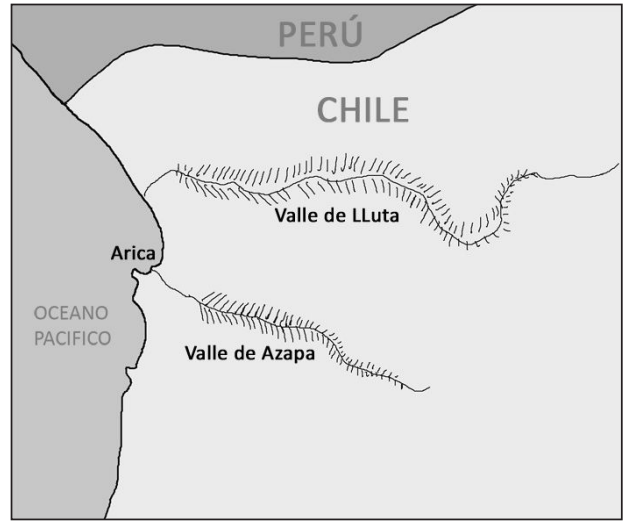

Figura 2. Mapa de ubicación de la ciudad de Arica respecto del valle de Azapa y el valle de Lluta.

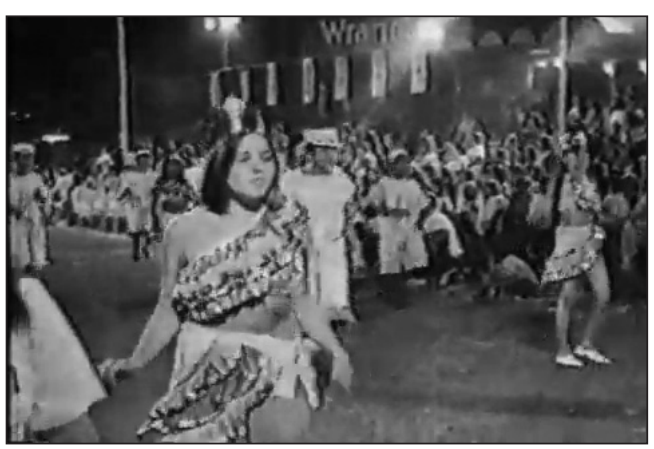

Figura 3. Pasacalle de comparsas vecinales de samba durante la Ginga realizada en el centro histórico de la ciudad de Arica. Fuente: http://www.youtube.com/watch?v=MDl_L $5 \mathrm{dg} \_\mathrm{gw}$

creando sus propios espacios y organizaciones sociales, económicas y culturales como estrategias de adaptación e integración a los medios urbanos. Surgen así grupos de choque o pandillas compuestas por jóvenes que aunque en algunos casos participan de agrupaciones culturales (p.e., celebración de santos patronos y organizaciones de baile como Caporal Asachi) y deportivas (p.e., Pucara de Putre); reaccionan a la experiencia de exclusión urbana enfrentándose a jóvenes no indígenas y a otros migrantes de precordillera y bolivianos en las mismas poblaciones, liceos y discotecas (Peña y Terán 2006). Según estos autores, la prensa escrita local (fundamentalmente la emitida por el diario La Estrella de Arica entre los años 1987-1991) los margina y estigmatiza, de modo que "no se excluyó al aymara boliviano, peruano o chileno, todos 
los aymara parecían de cierta forma integrantes de alguna de estas bandas" (Peña y Terán 2006: 83).

Por otra parte, tras un largo proceso de posicionamiento, ajuste y consolidación de las organizaciones aymara en la ciudad; la música y danzas de las festividades rurales (tarkeadas, laquitas, cacharpalla9 ${ }^{9}$ entre otras) así como las presentes en fiestas urbanas del altiplano (morenadas, caporales, tinkus, tobas, entre otras) emergen como alternativas de participación a través de las cuales los migrantes se reúnen y se convocan en la ciudad, a la vez que socializan e integran a las nuevas generaciones a los espacios urbanos conquistados.

En este sentido, observamos que así como valles y poblaciones estigmatizadas constituyeron espacios sociales desde donde se actualizaron prácticas performativas, el Carnaval Andino surge luego de la inscripción y posicionamiento de las primeras agrupaciones folclóricas aymara en la Ginga, fiesta de entretención y competencia ariqueña que contaba con la participación festiva de las Juntas de Vecinos. Éstas desfilaban con bailes de fantasía y/o samba, junto a carros alegóricos, por el casco histórico de la ciudad (Figura 3).

Una vez incorporadas las performances folclóricas de las agrupaciones aymara como categoría de competencia en la Ginga, en 1999 algunas agrupaciones se retiran de la competencia con la intención de crear y diseñar un evento cuya prioridad sea el folclore andino. Se crea entonces la Confraternidad de Bailes Andinos de Arica Inti Ch'amampi, y en el año 2002 se realiza el primer Carnaval Andino en la ciudad de Arica. De este modo, el carnaval constituirá un espacio de recreación de identidades étnico-nacionales que reunirá en tiempo festivo los principios de la cosmovisión aymara, la tradición folclórica boliviana y la gestión cultural de una ciudadanía chilena con características propias.

En el año 2007, la Asociación Indígena Confraternidad Agrupaciones Folclóricas Andinas de Arica, la Federación de la Cultura y las Artes Indígena Kimsa Suyu, y la Ilustre Municipalidad de Arica, definen y formalizan las Bases de Participación del Carnaval Andino Internacional "Inti Chamampi, Con la Fuerza del Sol". En ellas describen el carnaval como "la expresión popular de las raíces andi-

9 Voz quechua que significa acto y efecto de despedir o despedirse. nas expresadas en la danza y música, abarcando la macro región andina comprendida en las actuales fronteras de los países de Bolivia, Perú y Chile" (Bases Carnaval 2010: 1). Establecen de esta manera que este conjunto de expresiones son patrimonio de la sociedad civil aymara que se prepara para la proyección de Arica como capital del folclore andino de Chile.

\section{Significados y representaciones del Carnaval Andino}

El Carnaval Andino "Inti Ch'amampi, Con la Fuerza del Sol" se define como un espectáculo de competencia que lo singulariza respecto de los carnavales celebrados en otros puntos del área sur andina, donde priman los sentidos religiosos y/o agroganaderos (como es el caso del Carnaval de Oruro, o bien, de los carnavales celebrados en los pueblos de precordillera, cordillera y altiplano). Pese a esta diferencia, observamos que los significados atribuidos al desarrollo del carnaval en Arica se imbrican con los contenidos que tendría en los espacios locales o de origen, como lo es la cordillera o el altiplano:

"[Estas] fiestas marcan el tránsito de una temporada a otra a través del culto a sus deidades y antepasados y se orientan a celebrar la fertilidad como deseo de bienestar y abundancia, a la muerte-vida en un permanente ciclo del devenir" (Gavilán y Carrasco 2009: 103-104).

De esta manera, según Gavilán y Carrasco, el carnaval es representado como tiempo de reunión, juegos y alegría, donde "hombres y mujeres son los actores centrales. Como miembros de una unidad familiar tienen una ubicación estricta, por pueblo, por estancia y por comunidad" (2009: 106).

En el entendido de que la tradición no se define por la ausencia de cambios, sino en la "convicción de que la continuidad con el pasado es capaz de incorporar incluso las innovaciones y reinterpretaciones que exige el presente" (Gavilán 2005: 137-138), es posible visualizar la celebración del carnaval en contextos urbanos como una estrategia que permitiría "cultivar la propia suerte y vencer al destino" (Nash 2008 [1979]). En palabras de Nash:

"[...] independientemente de cuáles sean las conexiones que subyacen, es durante estos rituales que el espíritu de rebelión llega a 


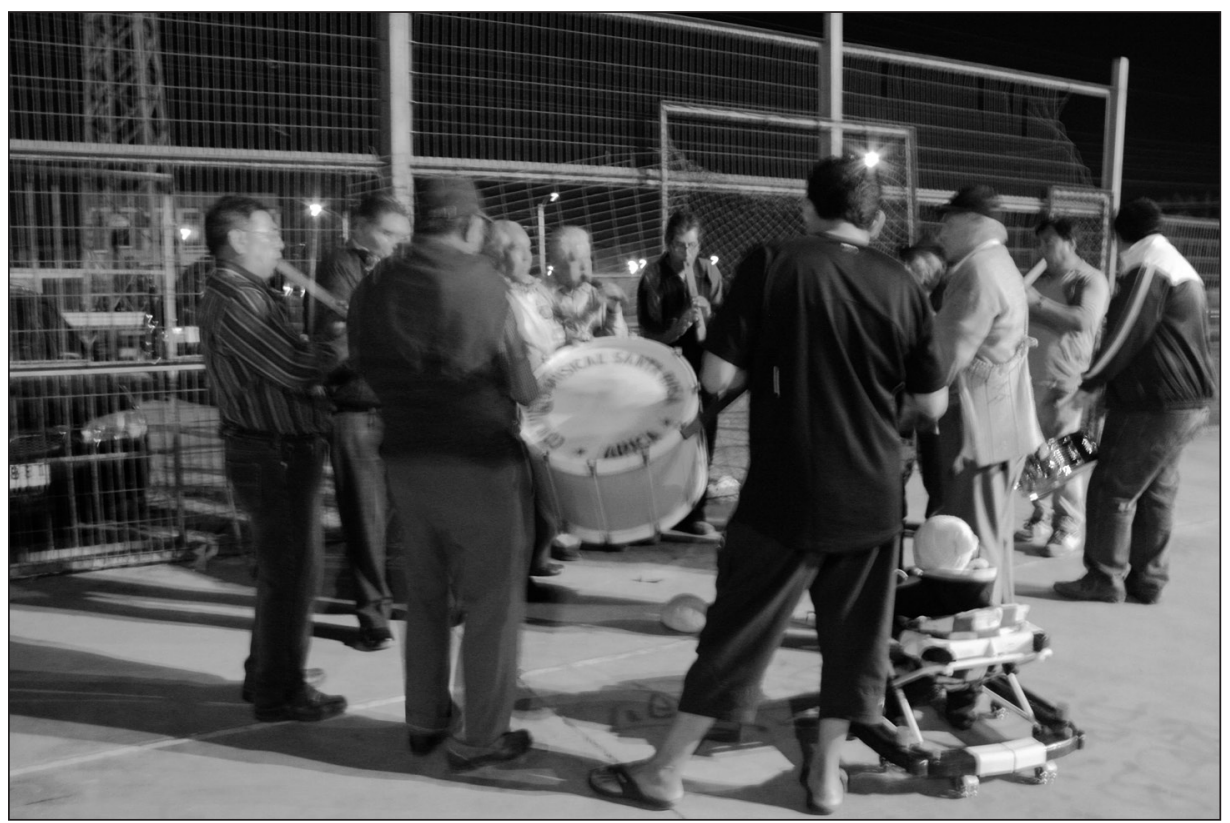

Figura 4. Ensayos del grupo de tarkeada de la agrupación "Hijos de Caquena", donde se observa la diversificada composición etárea del grupo de músicos. Fotografía de la autora.

la superficie. La resistencia toma muchas formas, pero es siempre reforzada por la autodeterminación de la gente que no ha perdido aún su propia identidad" (2008 [1979]: 199).

Observamos de esta forma que, aun cuando las agrupaciones de bailes busquen garantizar un lugar de encuentro que permita el ingreso de más personas sin distinción de procedencia étnica, en los hechos, es singular que la composición social de las agrupaciones remita a grupos extendidos de familiares y amigos de distintas edades (niños/as, jóvenes, adultos/as) que mantienen largas historias biográficas como bailarines/as urbanos. Esto permite comprender a las agrupaciones como espacios de cohesión donde ha sido posible reproducir social y simbólicamente relaciones ligadas a una herencia cultural andina (Figura 4).

En un mismo sentido, las actividades de preparación del carnaval configuran espacios de socialización en los que se actualizan y valoran los vínculos socioculturales. A modo de ejemplo, la gestión económica de ventas de comida (guatias, picantes y "polladas"), fiestas y bailables -acompañados de bandas de bronce y grupos de cumbia electrónica-, constituyen recursos culturales que aunque desplegados para recaudar fondos para la compra de trajes y contratar las bandas de música, permiten transmitir gustos, saberes y estéticas particulares, configurando formas de sociabilidad que recrean a la comunidad andina en la ciudad.

"Como quién dice, en carnaval... ahí se conocen las parejas y se forman las familias, entonces al carnaval van las chiquillas, se puede decir van adornadas. No es que se pinten, se adornan, es conquistar en el fondo, conquistar y supuestamente de ahí formar una nueva pareja. Es la tradición en el fondo, si de hecho creo que eso es lo que gatilla a que obviamente las agrupaciones de tarkeadas y todas las otras agrupaciones se hayan creado. En un principio era para eso y como todas venían de afuera, entonces ellos de alguna manera quieren cohesionarse y se creaban núcleos familiares, entonces todo eso está como relacionado" (bailarín Tinkus Kollas Wistus, diseñador web Anata.cl).

Asimismo, junto al carnaval urbano otras prácticas expresivas andinas han permitido vincular esta fiesta con el sentido cíclico de agradecimiento a la tierra. Se trata de la realización de prácticas rituales como pawas y "martes de challa", las cuales propician en distintos momentos del carnaval la fertilidad y buena fortuna de las acciones, 


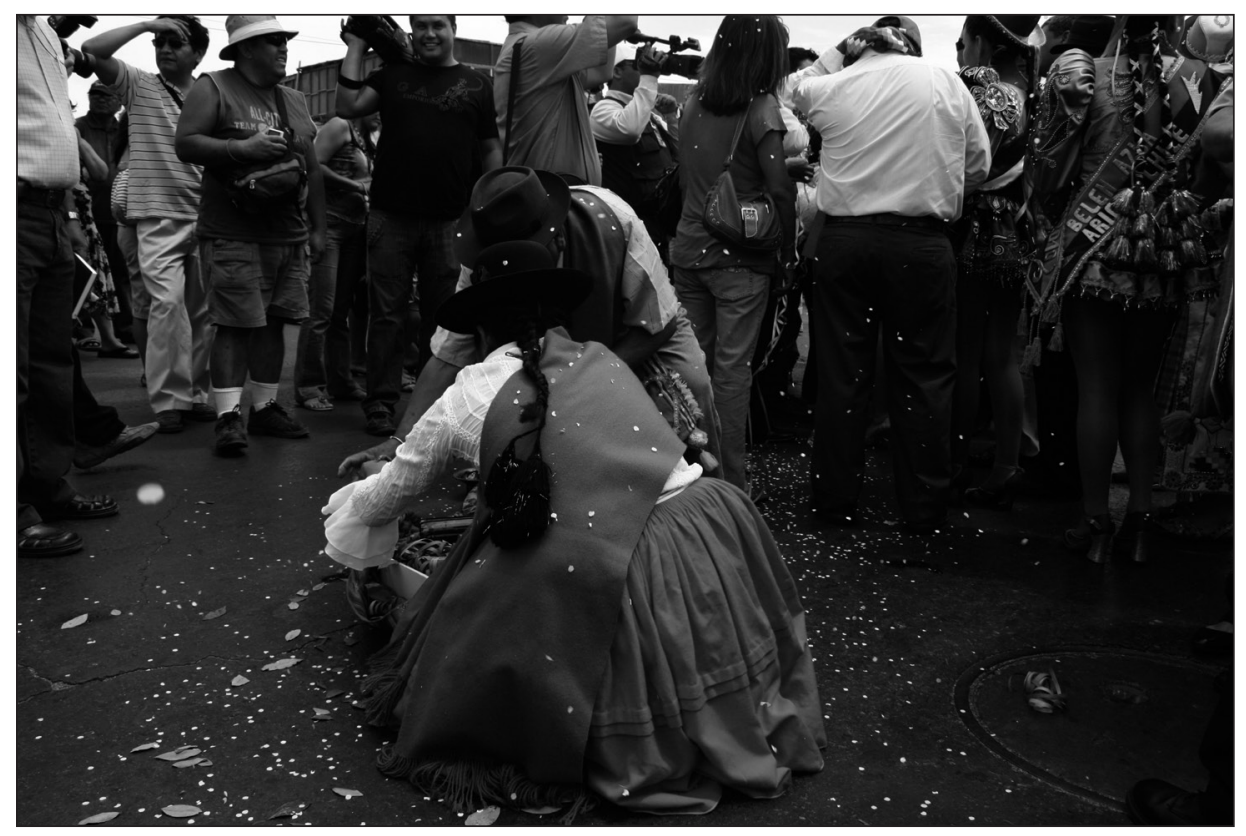

Figura 5. Pawa o "mesa" ritual en la inauguración del Carnaval Andino en Arica en calle Máximo Lira (centro histórico). Fotografía de Juan P. Donoso.

personas y objetos que emprenden un camino durante este tiempo festivo (trátese de agrupaciones, bailes, bailarines/as, trajes, u otros). En el caso de las pawas o "mesas" rituales, se trata de ceremonias cuya práctica se realiza para bendecir los emprendimientos en distintos momentos considerados de relevancia personal, familiar y/o comunitaria.

"Esa pawa que se llama, es pawar, es dar buenos augurios, nosotros quemamos un carrito con cigarros, con hojitas de coca y esa es la parte que uno se acuerda de nuestros ancestros, que vivieron ahí. Entonces uno siempre tiene que acordarse de los antepasados, porque ellos son pawa, ellos nos dejaron esas cuestiones a nosotros, la pawa, la mecha, esos son buenos augurios para que nos vaya bien pohy celebrando la vez que la ñusta salió, la ñusta es de la parte de la coronación, esa es la parte de ceremonia de ella, pero la pawa es general, para todos" (presidente "Hijos de Caquena").

En el caso de las agrupaciones de baile, observamos que su preparación y ejecución se emprende en fechas cercanas a la realización del carnaval, cuando se hace entrega solemne de los trajes a cada uno de los/as bailarines/as, así como para dar inicio a la competencia del carnaval en la partida del circuito (Figura 5).
"Se le agradece y se le pide permiso a la madre tierra, Pachamama, al Inti, se le pide permiso, que nos vaya bien. No se le pide ganar, no se le pide ganar plata, no se le pide ganar puesto en el carnaval. Se les pide que a los jóvenes no les pase nada, una buena salud, que disfruten la fiesta, que demuestren lo que ellos quieren hacer. Esas son nuestras costumbres" (bailarín "Tobas Andino Sajama”, presidente de la Confraternidad).

Por su parte, el "martes de challa" se desarrolla el último día del carnaval, antes del miércoles de cenizas que da inicio a la Cuaresma. Hace referencia a una práctica ritual realizada a nivel familiar y en espacios cotidianos, cuyo objetivo es agradecer a la Pachamama por los productos entregados, y rogar por la abundancia de los mismos. Para la consecución de ello se ofrecen serpentinas de colores, confites, alasitas o miniaturas, incienso, libaciones de alcohol, entre otros, a espacios y herramientas productivas tales como: chacras, oficinas, locales comerciales, camiones, herramientas, entre otros. Con este ofrecimiento ritual se bendice la actividad productiva realizada y se favorecen los productos del nuevo año. Si bien el "martes de challa" se vinculaba con las actividades agrícolas desarrolladas en el valle de Azapa, actualmente se realiza en el Terminal Agropecuario de Arica. Esto da 


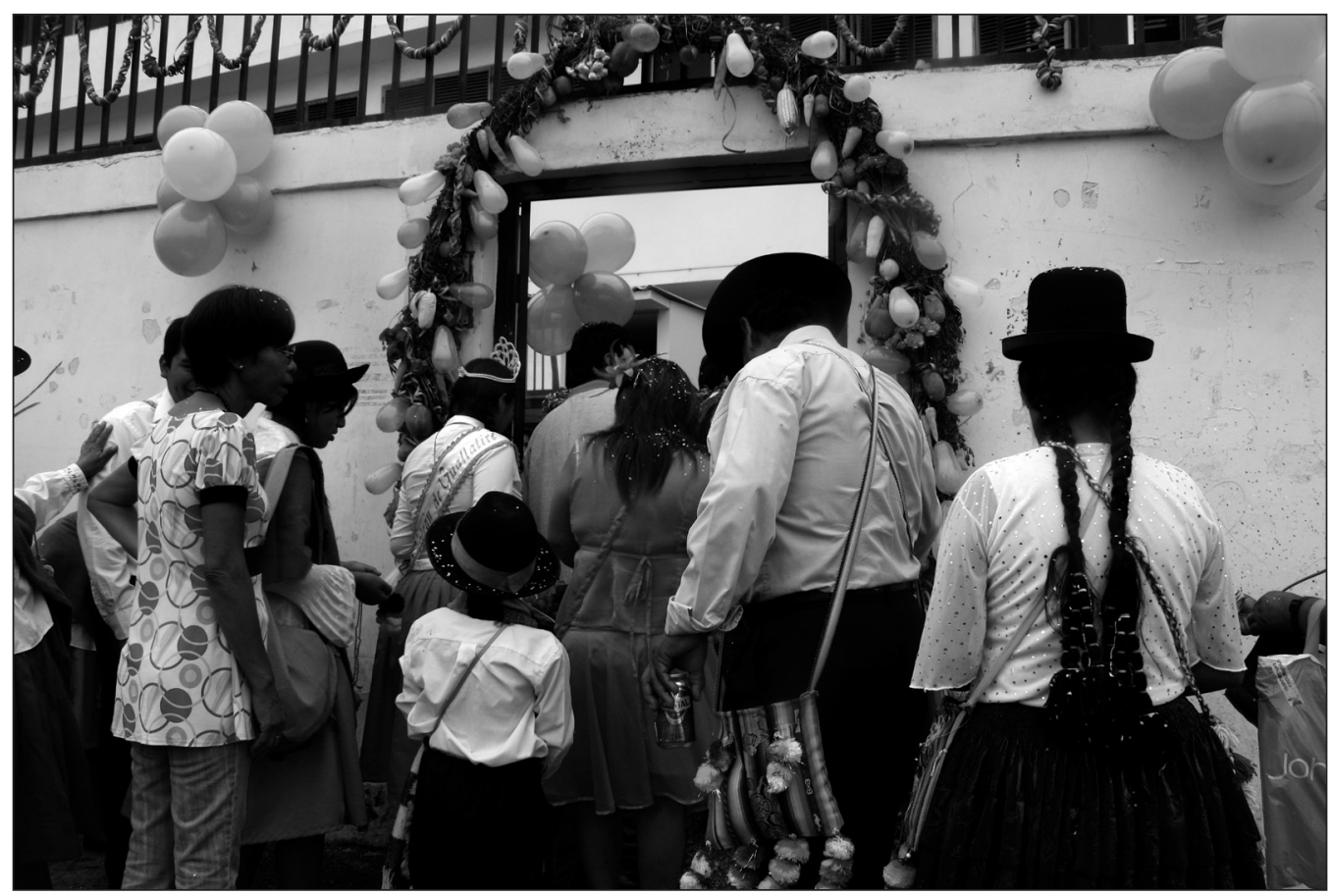

Figura 6. Bailarines/as provenientes de la precordillera y de los valles entrando a la oficina regional de la CONADI Regional para la celebración del "martes de challa". Fotografía de la autora.

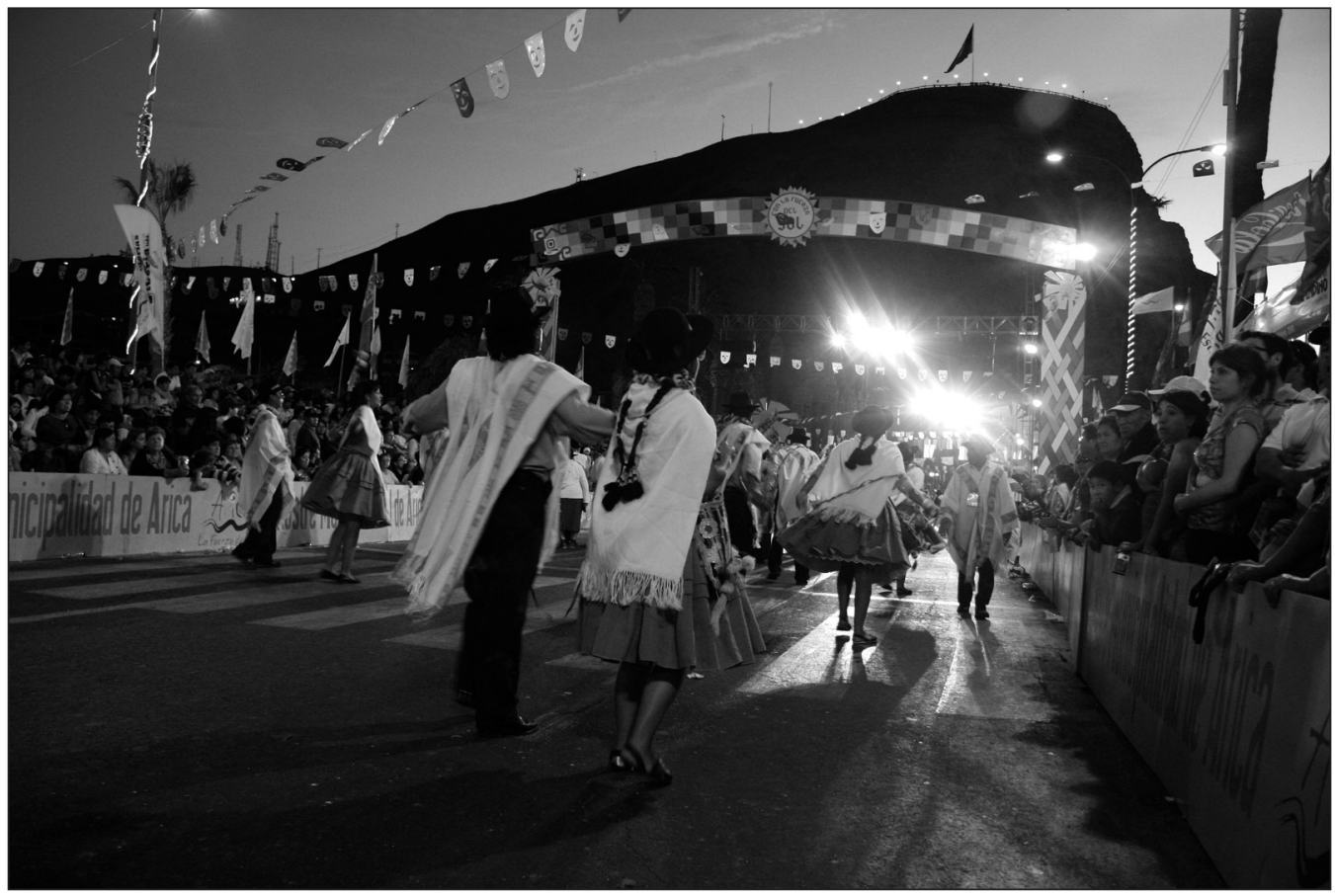

Figura 7. Agrupación "Hijos de Caquena" frente al Morro de Arica. Fotografía de Juan P. Donoso. 


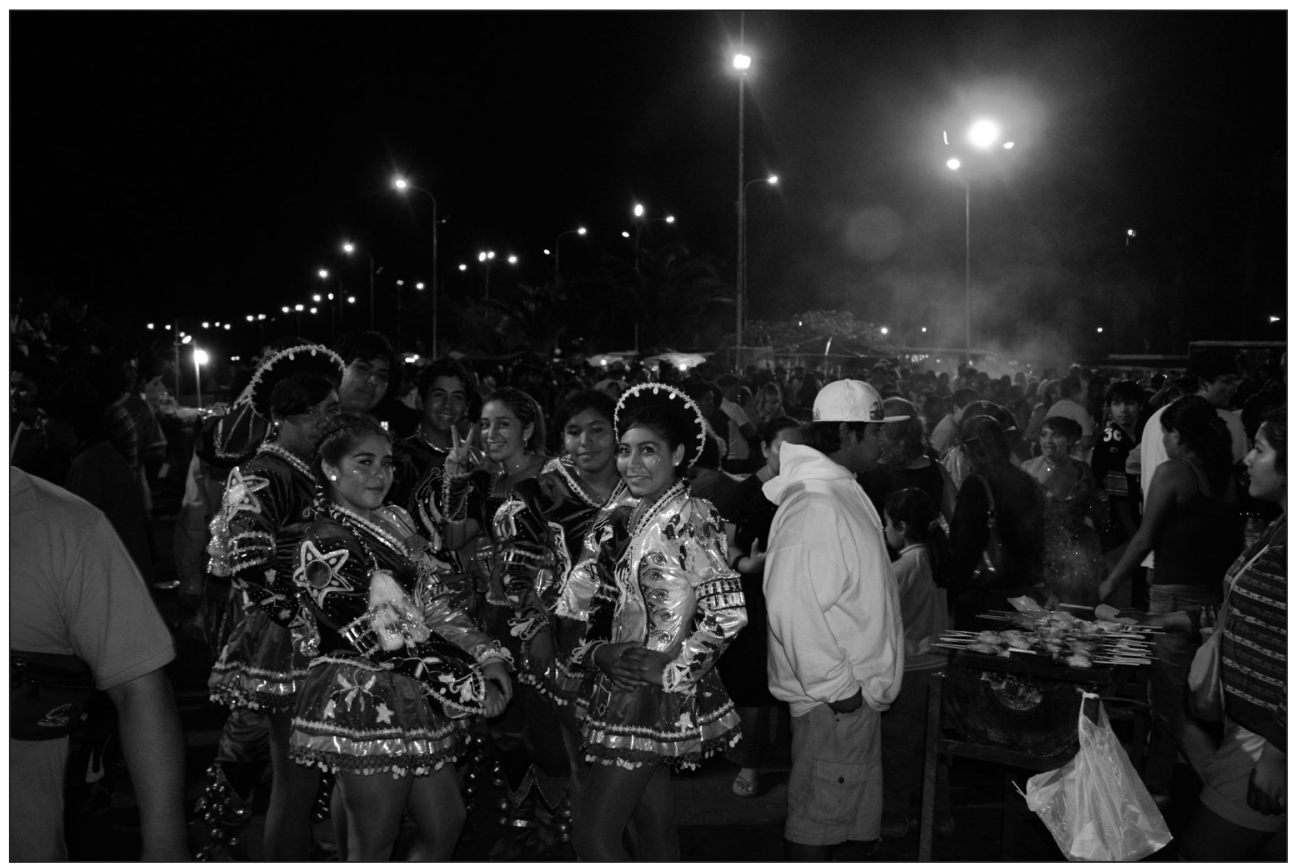

Figura 8. Plaza Vicuña Mackenna (Arica) durante el Carnaval Andino, donde bailarinas de caporales exhiben sus trajes con los colores de la bandera chilena, estrella y copihues. Fotografía de Juan P. Donoso.

cuenta de la importancia simbólica y económica de este espacio comercial para los residentes bolivianos, aymara y población en general, a la vez que refiere a la visibilidad que estas prácticas van adquiriendo en la urbe.

En este sentido, constatamos que desde fines de la década de 1990 la extensión y manifestación pública del "martes de challa" en el contexto urbano ha comenzado a plasmarse en las instituciones públicas del Estado, como lo son CONADI (Corporación Nacional de Desarrollo Indígena), Gobierno Regional, las municipalidades de Camarones y de Arica, entre otras. Al tiempo que las danzas andinas también constituyen estrategias identitarias para dar apertura y/o finalización o cacharpalla de las diversas actividades públicas realizadas (Figura 6).

"También tomó el tema la CONADI y también empezó a manejar el tema de 'martes de challa' que hacen los indígenas con una tarkeada y después empezó a visitar la... la icómo se llama? El municipio, la gobernación y algunos lugares, empezó en la población, en la ciudad. El "martes de challa" lo hace mucho tiempo, el agro... prácticamente ahí están las cholas prácticamente casi te atienden. Entonces ellos lo hacen hace mucho tiempo, ahí juegan a la challa, se tiran agua, llevan tarkeada. Si tú entrai vai a terminar mojada, bueno y eso es más antiguo. Entonces el concepto está bien arraigado y en todos lados se practica, costó si... porque en un principio miraban así medio raro. Ahora no, ahora ya saben ya, la gente ya lo conoce, lo ha visto y ha participado" (bailarín Tinkus Kollas Wistus, diseñador web Anata.cl).

En la actualidad, el Carnaval Andino es reconocido institucionalmente por el municipio de Arica y el Gobierno Regional. No es casual que la utilización del eslogan "La Fuerza del Sol" como emblema del municipio constituya una de las estrategias de apropiación simbólica del evento, a la vez que exprese la permeabilidad de la institucionalidad pública respecto a la gestión cultural de las agrupaciones indígenas. Sin embargo, han sido el carácter fronterizo de la ciudad y la composición étnica de las organizaciones de baile, los ejes que han permitido situar al Carnaval Andino como una festividad de relevancia en el contexto del área sur andina. Con esto destacamos la preponderancia del sostenido intercambio económicocultural que la población andina ha mantenido en torno a este espacio fronterizo: 
"Tenemos una tradición, una tradición de carnavales que va subiendo, la gente ya no viaja a Cusco, la gente de Chile ya no viaja a Oruro, viene a ver el carnaval de Arica, la gente de Tacna viene a ver el carnaval de Arica, la gente de La Paz viene a ver el carnaval de Arica, porque tiene una competencia , y ellos ven... este carnaval no está inserto en el tema de la Virgen, allá son dos días... acá son tres días de competencia [...] lo de competencia es lo que no tienen los otros países y eso le ha gustado a otros países" (bailarín "Tobas Andino Sajama", presidente de la Confraternidad).

Todas estas dimensiones han generado formas de identificación asociadas a la experiencia positiva de haber construido un Carnaval Andino en la ciudad de Arica. En este caso, observamos un doble "orgullo": por una parte, el que sean las prácticas expresivas andinas las que hayan permitido situar a la ciudad en un lugar de reconocimiento a nivel nacional e internacional y, por otra parte, la identificación con la ciudad de Arica. Esto hace del carnaval un producto andino recreado por aymara que se definen como ariqueños/as, dimensiones identitarias que -desde esta perspectiva- permiten apelar a este espacio festivo como la posibilidad de mostrarse en términos étnicos y regionales a una audiencia nacional e internacional. Es especialmente significativo el interés por visualizarse culturalmente respecto de la zona central del país, ya que se concibe que es ésta la tribuna de legitimación institucional donde se debe apelar por el reconocimiento, evocando un imaginario de nación respecto del cual se desea agregar la memoria y experiencia social, cultural y estética de los pueblos andinos (Figura 7).

\section{$*$ Conclusiones}

Observamos que las calles del centro histórico de la ciudad de Arica versus el espacio periférico de las poblaciones donde se asientan la mayoría de migrantes aymara y población popular en general, constituyen una cartografía que permite visualizar, explorar y problematizar el carácter de las performances de las asociaciones indígenas. De este modo, durante el Carnaval Andino "Inti Ch'amampi, Con La Fuerza del Sol", repertorios culturales como música y danzas constituyen memorias corporales que, al mismo tiempo que vinculan social y afectivamente con una idea de colectividad andina representada en las tradiciones folclóricas bolivianas, conforman estrategias que permiten posicionarse y "mostrarse" en la ciudad en términos de una legítima ciudadanía. No obstante, esta recontextualización y reinvención de las expresiones culturales andinas en una ciudad fronteriza como Arica, debe responder a las narrativas de autenticidad que ponen al pueblo rural como garante de la identidad indígena, o bien atender a los reclamos por la "usurpación" de bailes patrimoniales bolivianos. Esta controversia revela la compleja manifestación y construcción de identidades en un escenario de frontera en el cual, sin embargo, la mayoría de los/ as bailarines/as reconoce una ascendencia boliviana y/o peruana, pero principalmente un origen aymara.

Por una parte, la búsqueda de reconocimiento, aceptación o legitimidad social de estas prácticas en espacio chileno permite comprender las performances como una de las posibilidades de construir nuevas formas de sociabilidad y expresión pública de diferencia. De esta manera, al tiempo que la construcción de ciudadanía indígena chilena ha enfatizado el carácter político de la producción de narrativas propias (Zapata 2004) ${ }^{10}$, observamos que estas estrategias de visualización festiva configuran prácticas públicas que complementan los espacios de representación conquistados. Por otra parte, así como lo nacional se ubica simbólicamente en el centro político del país respecto del cual se busca reconocimiento, lo internacional emerge no solo como una tribuna promocional, sino que remite a la red de relaciones transfronterizas que los actores andinos han mantenido respecto de la constitución histórica de este territorio, pues el desarrollo del Carnaval Andino -así como los carnavales tradicionales- permiten reunir en un mismo espacio y tiempo a la sociedad aymara migrante (chilena, boliviana, peruana), forjando un sentido de integración social y cultural que permitiría recrear un sentido de comunidad que trasciende y reelabora la lógica de fronteras (Figura 8).

\footnotetext{
${ }^{10}$ Durante el año 2002, casi 10 años después de haber sido promulgada la Ley Indígena, Zapata (2004) constata que la pluralidad de liderazgos aymara -fundamentalmente universitarios y urbanos - no ha logrado resolver la apelación a la localidad rural tradicional como núcleo de sus identidades versus su anclaje en las ciudades. Así, la manifestación de la diferencia fluctúa entre un discurso escrito que apela a la construcción de un relato histórico de la identidad, contra el reconocimiento de la pérdida de saberes tradicionales (lengua, referencias geográficas, entre otros) dados por el acceso a la educación formal.
} 
Agradecimientos Este trabajo y reflexiones son resultado de la investigación doctoral en curso: "Performance y representación: Fiesta y ritual entre pueblos andinos" desarrollado en la ciudad de Arica, dentro del Programa de Doctorado en Antropología de la Universidad Católica del Norte, Chile. Agradezco de corazón el apoyo brindado por los dirigentes y bailarines/as de la "Confraternidad de Bailes Folclóricos Andinos de Arica", quienes me invitaron a las instancias de presentación pública de sus agrupaciones en la ciudad y me alentaron en el registro de sus bailes. Agradezco en especial a don Luis Díaz, por transmitirme la energía y pasión por el desarrollo del Carnaval Andino en Arica, a Cristián Santos y Rafael Chuquimia por su preciso conocimiento respecto del desarrollo de las prácticas expresivas andinas en esta región fronteriza. Agradezco también a la agrupación "Hijos de Caquena", en especial a Doroteo Calle y Lorena Calle, que me guiaron en el aprendizaje de la tarkeada, y a Félix Poma, quien fue mi guía de baile en el Carnaval Andino del año 2010.

\section{$*$ Referencias citadas}

BÁEZ, C., 2010. Lumbanga; memorias orales de la cultura afrochilena. Herco Editores S.A., Arica.

BASES PARTICIPACIÓN IX VERSIÓN CARNAVAL ANDINO INTERNACIONAL CON LA FUERZA DEL SOL, 2010. Ilustre Municipalidad de Arica, Decreto 6678/18 dic. 2009. www.anata.cl.

CÁNEPA, G., 2001. Identidades representadas. Performance, experiencia y memoria en los Andes. Pontificia Universidad Católica del Perú, Fondo Editorial, Lima.

CHIPANA, C., 1986. La identidad étnica de los aymaras en Arica. Chungara 16-17: 251-261.

CITRO, S., 2009. Cuerpos significantes. Travesías de una etnografía dialéctica. Editorial Biblos/ Culturalia, Buenos Aires.

DÍAZ, A., 2009. Los Andes de bronce. Conscripción militar de comuneros andinos y el surgimiento de las bandas de bronce en el norte de Chile. Historia 42 (II): 371-399.

DÍAZ, A., R. RUZ y C. MONDACA, 2004. La administración chilena entre los aymaras: Resistencia y conflicto en los Andes de Arica (1901-1926). Anthropologica 22 (XII): 216-231.

GAVILÁN, V., 2005. Representaciones del cuerpo e identidad de género y étnica en la población indígena del norte de Chile. Estudios Atacameños 30: 135-148.

GAVILÁN, V. y A. CARRASCO, 2009. Festividades andinas y religiosidad en el norte chileno. Chungara, Revista de Antropología Chilena 41 (1): 101-112.

GONZÁLEZ, H., 1995. La inserción económica de los migrantes aymara en la ciudad. El trabajo como empresa familiar y la repro- ducción cultural. Actas del Segundo Congreso Chileno de Antropología, vol. 1, pp.315-324. Valdivia.

1997. Apuntes sobre el tema de la identidad cultural en la región de Tarapacá. Estudios Atacameños 13: 9-26.

2003. Los aymaras contemporáneos. En Conozcamos juntos la historia y cultura de nuestra región, A. M. Carrasco y B. Cofré (Eds.), pp. 39-45. Programa Explora-CONICYT, Gobierno Regional de Tarapacá, Centro de Investigaciones del Hombre del Desierto (CIHDE), Taller de Estudios Andinos (TEA), Arica.

GONZÁLEZ, H. y H. GUNDERMANN, 1996. Organizaciones aimaras, identidad étnica e integración. En La integración surandina. Cinco siglos después, X. Albó, M. I. Arratia, J. Hidalgo, L. Núñez, A. Llagostera, M. I. Remy, B. Revesz (Comps.), pp. 395-416. Estudios y Debates Regionales Andinos 91, Centro de Estudios Regionales Andinos Bartolomé de Las Casas, Corporación Norte Grande Taller de Estudios Andinos, Universidad Católica del Norte, Antofagasta.

GONZÁLEZ, H. y V. GAVILÁN, 1990. Cultura e identidad étnica entre los aymaras chilenos. Chungara 24-25: 145-158.

Ms., s/f. Cultura e identidad étnica entre los aymaras chilenos. Taller de Estudios Aymara, Arica.

GREBE, M. E., 1986. Migración, identidad y cultura aymara: Puntos de vista del actor. Chungara 16-17: 205-223.

GUBER, R., 2005. El salvaje metropolitano. Editorial Paidós, Buenos Aires.

GUNDERMANN, H., 1997. Etnicidad, identidad étnica y ciudadanía en los países andinos y el norte de Chile. Los términos de la 
discusión y algunas hipótesis de investigación. Estudios Atacameños 13: 9-26.

1998. Comunidad aymara, identidades colectivas y Estados nacionales en los albores del siglo XX. En $A 90$ años de los sucesos de la escuela Santa María de Iquique, P. Artaza (Ed.), pp. 153-181. LOM Ediciones, Dirección de Biblioteca, Archivos y Museo (DIBAM), Santiago.

2003. Las poblaciones indígenas andinas de Chile y la experiencia de la ciudadanía. En Mapuches y aymaras. El debate en torno al reconocimiento y los derechos ciudadanos, $\mathrm{H}$. Gundermann, R. Foerster y J. I. Vergara (Eds.), pp. 19-104. Predes, Universidad de Chile, RIL Editores, Santiago.

GUNDERMANN, H. y J. I. VERGARA, 2009. Comunidad, organización y complejidad social andinas en el norte de Chile. Estudios Atacameños, Arqueología y Antropología Surandinas 38: 107-126.

GUNDERMANN, H., I., VERGARAy R. FOERSTER, 2005. Contar a los indígenas en Chile. Autoadscripción étnica en la experiencia censal de 1992 y 2002. Estudios Atacameños 30: 91-115.

INSTITUTO NACIONAL DE ESTADÍSTICAS (INE), 2003. Estadísticas sociales de los pueblos indígenas en Chile. Censo 2002. MIDEPLAN / BID.

\section{INFORME DE LA COMISIÓN VERDAD HISTÓRICAY NUEVO} TRATO CON LOS PUEBLOS INDÍGENAS, 2008. Comisionado Especial para Asuntos Indígenas, Santiago.

LEÓN, M., 2012. El proceso de visibilización, valoración patrimonial y reconstrucción de memoria de los afrodescendientes en Chile. Actas del Tercer Congreso Latinoamericano de Antropología (ALA). Santiago (2012)

NASH, J., 2008 [1979]. Comemos a las minas y las minas nos comen a nosotros. Dependencia y explotación en las minas de estaño bolivianas, pp. 153-200. Antropofagia, Buenos Aires.

PEÑA, J. y P. TERÁN, 2006. Pandillas de jóvenes aymaras en la ciudad de Arica (1987-1991): Los chaperones y los masa. Seminario para optar al título de profesor en enseñanza media en
Historia y Geografía. Departamento de Ciencias Geográficas e Históricas, Facultad de Educación y Humanidades, Universidad de Tarapacá, Arica.

PLATT, T., 1975. Experiencia y experimentación: Los asentamientos andinos en las cabeceras del valle de Azapa. Chungara 5: 33-60.

PODESTÁ, J., 2004. La invención de Tarapacá. Estado y desarrollo regional en Chile. Ediciones Campus, Universidad Arturo Prat, Iquique.

RECABARREN, D. y L. VALERA, 2006. Análisis de dos festividades en San Miguel de Azapa (2004-2006). Carnaval de Verano y el Día de los Difuntos. Seminario para optar al título de Profesor de Educación Media de Historia y Geografía. Departamento de Ciencias Históricas y Geográficas, Facultad de Educación y Humanidades, Universidad de Tarapacá, Arica.

SCHECHNER, R., 2000. Performance. Teoría y prácticas interculturales. Secretaría de Extensión Universitaria y Bienestar Estudiantil, Universidad de Buenos Aires, Buenos Aires.

TABILO, K., F. VENEGAS y H. GONZÁLEZ, 1995. Las agrupaciones de residentes aymara urbanos en el norte de Chile:Adaptación a la ciudad y vínculos con las comunidades de origen. Serie de Documentos de Trabajo, Corporación Norte Grande, Arica.

TUDELA, P., 1990. Chilenización y cambio ideológico entre los aymaras de Arica (1883-1930). Intervención religiosa y secularización. Revista Chilena de Antropología 12: 1-19.

VAN KESSEL, J., 1996. Los aymaras contemporáneos de Chile. En Etnografía. Sociedades indígenas contemporáneas y su ideología, J. Hidalgo, V. Schiappacasse, H. Niemayer y P. Mege (Eds.), pp. 47-68. Editorial Andrés Bello, Santiago.

ZAPATA, C., 2001. Las voces del desierto: Identidad aymara en el norte de Chile. Dirección de Bibliotecas, Archivos y Museos (DIBAM), Centro de Investigaciones Diego Barros Arana, RIL Editores, Santiago.

2004. Atacameños y aymaras. El desafío de la "verdad histórica". Estudios Atacameños 27: 169-187. 